Aquaculture

January 2016, Volume 451 Pages 11-15

http://dx.doi.org/10.1016/j.aquaculture.2015.08.032

http://archimer.ifremer.fr/doc/00277/38835/

(c) 2015 Elsevier B.V. All rights reserved.

\title{
Gamete quality in triploid Pacific oyster (Crassostrea gigas)
}

\author{
Suquet Marc ${ }^{1,{ }^{*}}$, Malo Florent ${ }^{1}$, Quere Claudie ${ }^{2}$, Ledu Christophe ${ }^{3}$, Le Grand Jacqueline ${ }^{1}$, \\ Benabdelmouna Abdellah ${ }^{3}$
}

${ }^{1}$ Ifremer, UMR 6539 Lemar, PFOM Department, Station Expérimentale d'Argenton, Argenton, France

${ }^{2}$ Ifremer, UMR 6539 Lemar, PFOM Department, Technopole Brest-Iroise, Plouzané, France

${ }^{3}$ Ifremer, SG2M, Laboratory of Genetics and Pathology of Marine Molluscs, La Tremblade, France

*Corresponding author : Marc Suquet, email address : msuquet@ifremer.fr

\begin{abstract}
:
Triploidy induction in shellfish aims to obtain faster growth and sterility of reared individuals. Triploid Pacific oysters are most often not totally sterile, but have greatly reduced reproductive capacities compared to those recorded in diploid individuals. The description of gamete output in triploid aquatic animals is most often confined to the assessment of fecundity in females. The present work aims at further describing gamete quality of triploid Pacific oysters and comparing it to values observed in diploid individuals. Diploid and triploid oysters (produced by mating tetraploid males $\times$ diploid females) were reared in standard conditions and then transferred to the wild to allow the offspring to attain reproductive maturity. At the end of gametogenesis, the reproductive characteristics of both groups were estimated.
\end{abstract}

After gonad sampling, gametes could be observed in $92.9 \%$ diploid oysters compared with $42.0 \%$ in triploids. A higher number of spermatozoa was produced in diploids (344 $\pm 106 \times 109$ spermatozoa) compared with triploids ( $5 \pm 7 \times 109$ spermatozoa). Furthermore, the percentage of motile sperm and sperm swimming speed were higher in diploids compared with triploids. In contrast, a higher intracellular ATP content was found in triploids $(99.1 \pm 34.0$ nmole $10-9$ sperm) than in diploids $(63.6 \pm 20.7$ nmole 10- 9 sperm). A higher number of oocytes was collected from diploid oysters $(19.1 \pm 3.8 \times 106$ oocytes), than from triploid ones $(0.1 \pm 0.1 \times 106$ oocytes). The D-larval yield was $45 \%$ higher for crosses (female $\times$ male) triploid $\times$ diploid, than the control (diploid $\times$ diploid). Furthermore, the lowest $D$ larval yield was measured for triploid $\times$ triploid crosses.

Considering the present data, a partial estimation of the reproductive potential of triploid Pacific oysters (triploid $\times$ triploid crosses) could be close to $0.06 \%$ of that of diploid individuals. However, this estimation is probably over-evaluated because it does not take into account the low sperm production of triploids (1.5\% compared to diploids), the unknown frequency of spontaneous spawning in triploids and the low viability of the progeny. The consequences of the low reproductive potential of triploid Pacific oysters on natural populations and on hatchery practices are discussed. In conclusion, the present work confirms that triploidy leads to a limited reproductive potential as estimated by gamete characteristics and embryo developmental success. Statement of relevance This study is relevant to aquaculture because triploids are produced by aquaculture and the consequences of their low gamete quality, described in this paper, on the natural environment but also on hatchery practices are discussed. 


\section{Highlights}

- Triploids account for $30 \%$ of worldwide Pacific oyster aquaculture production. $\rightarrow$ A panel of biodescriptors provided the first picture of gamete quality in triploid Pacific oysters. The reproductive potential of triploid Pacific oysters could be close to $0.06 \%$ of that of diploid. The low gamete quality observed in triploid Pacific oysters decreases the genetic impact on natural populations and modifies aquaculture practices.

\section{Statement of relevance}

This study is relevant to aquaculture because triploids are produced by aquaculture and the consequences of their low gamete quality, described in this paper, on the natural environment but also on hatchery practices are discussed.

Keywords : Crassostrea gigas, Reproduction, Triploidy, Gamete 


\section{Introduction}

The induction of triploidy in shellfish aims to obtain a faster growth and sterility of reared animals, by relocation of energy from reproduction to growth (Piferrer et al., 2009). A superior flesh flavour of triploids has also been reported by consumers due to a firmer texture and a more constant flesh quality throughout the year, resulting from reducted reproductive effort (Nell, 2002). These economically beneficial characteristics have led to triploidy being used in a large range of farmed molluscs including Pacific oyster, in which triploids account for $30 \%$ of worldwide production (Dunham, 2011).

Triploids are usually not totally sterile, but their reproductive capacities are much reduced compared with those recorded in diploid individuals. In fish species, triploid females rarely produce eggs and those that there are produced are generally unfertilisable (Piferrer et al., 2009). In Atlantic cod (Gadus morhua), the hatching success of offspring was halved when sperm collected from triploid males was used to fertilize eggs, compared with results obtained using diploid males (Feindel et al., 2010). In crustacean species, triploid females or males of black tiger shrimp (Penaeus monodon) do not produce viable gametes (Sellars et al., 2013). In shellfish, the potential to produce viable scallop (Pactinopecten yessoensis) offspring from triploid breeders was estimated to be $4 \times 10^{-6} \%$ of diploid ones (Meng et al., 2012).

In oysters, polyploidy was first induced in the American oyster (Crassostrea virginica) in the early 1980 s, by inhibiting polar body expulsion using cytochalasin B (Stanley et al., 1981). To avoid chemical toxicity, triploids have been more recently produced by crossing tetraploid oysters with diploid ones, leading to all-triploid oyster progenies (Guo et al., 1996).

Regarding their reproductive capacity, gonad development of triploid oysters is reduced: triploids show active gametogenesis during the first stages but their gonad development is then blocked, with most triploids remaining at early stages of gametogenesis (Jouaux et al., 2010; Normand et al., 2008). However, it is possible to collect functional gametes by gonad stripping in certain breeders of both sexes, and larvae can be obtained after controlled crosses of diploids $\times$ triploids or triploids $\times$ triploids. The fecundity of triploid females is low and was found to vary from $2 \%$ to $13 \%$ of diploid levels (Gong et al., 2004; Guo and Allen, 1994). Additionally, the reproductive potential of triploid Pacific oysters was estimated to be $0.0008 \%$ of diploid ones (Guo and Allen, 1994). No previous studies on reproductive capacities of triploid oysters have described gamete quality of these breeders.

A panel of bio-descriptors can provide a complete picture of gamete quality in aquatic species, including gamete concentration and morphology, sperm motility, intracellular energy content and fertilization capacity (Fauvel et al., 2008). The present work aims to describe gamete quality of triploid Pacific oysters and compare it with that observed in diploid individuals.

\section{Materials and methods}

\subsection{Broodstock conditioning and gamete collection}

The oysters used in the present study were produced in 2012 at the Ifremer experimental hatchery in La Tremblade (Charente, France). To produce diploid and triploid oysters, 30 diploid females, 10 diploid males and 15 tetraploid males were selected as genitors. Diploid oysters were three-year-old individuals, bought from local oyster farmers working exclusively 
with wild-caught spat. These diploid oysters were conditioned to full maturation in an open circulating system at $20-22^{\circ} \mathrm{C}$. Tetraploid oysters used to produce triploid progeny in this work, were two years old and were conditioned to maturation in the same conditions as the diploids, but in a quarantine area equipped with water treatment systems using ozone to prevent dissemination of gametes or larvae. Tetraploid oysters were used as males and sampled from the same tetraploid broodstock used for the mass production of triploids by French commercial hatcheries. This tetraploid broodstock was initially produced in 2006 in the Ifremer experimental hatchery using diploid $\times$ diploid crosses according to the method developed by Benabdelmouna and Ledu (2007).

At the end of oyster gametogenesis, gametes were collected from diploid and tetraploid oysters by gonad stripping, then suspended in $1 \mu \mathrm{m}$ filtered sea water (FSW, $24^{\circ} \mathrm{C}$ ). Eggs from the 30 diploid females were collected and divided into two pools. The first pool was fertilized using sperm collected from the 10 diploid males to produce diploid larvae, and the second pool was fertilized by sperm from the 15 tetraploid males, to produce triploid larvae. Then, these diploid and triploid larvae were transferred to $150 \mathrm{~L}$ tanks filled with $\mathrm{FSW}$ and cultured under standard rearing conditions until metamorphosis $\left(24^{\circ} \mathrm{C}, 100\right.$ larvae $\mathrm{mL}^{-1}$, fed with a mixture of microalgae: Isochrysis galbana, Chaetoceros gracili and Skeletonema costatum). DNA ploidy level of each batch was regularly verified by flow cytometry, according to Barranger et al. (2014).

When the spat reached $2 \mathrm{~mm}$, they were transferred to the Ifremer nursery in Bouin (France) for intensive growth using raw sea water enriched with Skeletonema costatum (June 2012 to October 2013). From the end of 2013, adult diploid and triploid oysters were reared in the field at La Floride (Marennes-Oléron bay, France) bay until the end of July 2014, when they were fully ripe.

\subsection{Gamete quality analysis}

At the end of the conditioning period, the DNA ploidy level was again individually verified by flow cytometry for all the diploid and triploid oysters. Mature Pacific oysters (diploid $n=20$, triploid $n=70$ ) were then transferred to the experimental hatchery in Argenton (Ifremer, Northern Brittany, France). They were maintained in a conditioning environment, according to Song et al. (2009). Oyster whole weight (W) and flesh weight following superficial drying with soft paper $(F W)$ were measured and condition index was calculated: $\mathrm{Cl}=(\mathrm{FWN})^{\star} 100$, according to Royer et al. (2008). In order to determine their sex, six samples were pipetted from the gonad of each oyster (covering the whole gonad volume). Diploid and triploid oysters were stripped in seawater $\left(33.7\right.$ salinity, $\left.19^{\circ} \mathrm{C}\right)$.

Sperm density was assessed using a Thomas cell after gamete dilution in seawater (ranging from 1:1 to $1: 25$, depending on individual sperm concentration). The total number of spermatozoa collected from each oyster was calculated (gamete density $\times$ seawater volume). To estimate sperm motility, sperm was diluted in an activating solution (AS: seawater, $5 \mathrm{~g} \mathrm{~L}^{-1}$ bovine serum albumin, Tris $20 \mathrm{mM}, \mathrm{pH} 8.10$, caffeine $10 \mathrm{mM}$, dilution rate: 1:9). Sperm movement was observed at 10 minutes and $2 \mathrm{~h}$ post activation under a phase contrast microscope (Olympus BX51, × 10 magnification) and recorded (Sony camera, 60 frames $\mathrm{s}^{-1}, 4 \mathrm{~s}$ film duration, $3 \times 30$ spermatozoa). Then, sperm motility characteristics (percentage of motile sperm and Velocity of the Average Path: VAP) were assessed using a CASA plugin developed for image J, according to Suquet et al. (2014). To measure intracellular ATP content, $10^{7}$ sperm in $500 \mu \mathrm{L}$ seawater were transferred into $2 \mathrm{~mL}$ cryotubes. ATP was assessed in triplicates by bioluminescence (ATP lite kit, Perkin Elmer). 
Oocyte density was estimated by microscopic counts $(3 \times 50 \mu \mathrm{L}$ in $10 \mathrm{~mL}$ to $2 \mathrm{~L}$, depending on individual oocyte concentration). Total number of oocytes collected from each oyster was calculated (gamete density $\times$ seawater volume). Furthermore, morphological characteristics of oocytes (Feret diameter, perimeter, area and circularity ranging from 0 to 1 , where a value of 1 indicates a perfect circle) were assessed 30 minutes after gonad stripping, using Image $J(n=30$ oocytes).

Triplicate batches of 25000 oocytes each were then fertilized according to the following crosses (female $\times$ male): diploid $\times$ diploid $(n=5)$, diploid $\times$ triploid (4), triploid $\times$ diploid $(2)$, triploid $\times$ triploid (3). Oocytes were fertilized using a non-limiting sperm to egg ratio $(500)$. Oocyte lots were incubated in $2 \mathrm{~L}$ beakers and the D-larval yield was estimated $48 \mathrm{~h}$ post fertilization: (number of D-larvae / 25000 )*100.

\subsection{Statistical analysis}

Data are presented as mean \pm standard deviation. Percentages (D-larval yield) were arcsin square root transformed before analysis. Means were compared using Student t tests or ANOVA. For ANOVA and when differences were significant $(P<0.05)$, a Fisher a posteriori test was used for mean comparisons. Because variances were not homogeneous, morphological data on oocytes were compared using a non parametric Mann and Whitney test.

\section{Results}

The whole weight of triploid oysters $(99.3 \pm 28.4 \mathrm{~g})$ was significantly higher $(P=0.014)$ than that observed in diploid ones $(81.4 \pm 24.4 \mathrm{~g})$. Inversely, the condition index was significantly lower $(P=0.001)$ in triploid oysters $(13.9 \pm 1.6)$ than in diploid ones $(16.2 \pm 3.0)$. After gonad sampling, gametes could be observed in $92.9 \%$ diploid oysters compared with $42.0 \%$ in triploids. No simultaneous hermaphrodites were observed in either group.

In males, a significantly $(P=0.001)$ higher number of spermatozoa was produced in diploids $\left(344 \pm 106 \times 10^{9}\right.$ spermatozoa) than in triploids, $\left(5 \pm 7 \times 10^{9}\right.$ spermatozoa, Fig. $\left.1 \mathrm{~A}\right)$. Furthermore, the percentage of motile sperm and VAP were significantly higher $(P=0.005$ and $P=0.001$, respectively) in diploids, than triploids (Fig 1B and $C$ ). A significantly higher $(P$ $=0.047)$ intracellular ATP content was found in triploids $\left(99.1 \pm 34.0\right.$ nmole $10^{-9}$ sperm $)$ than diploids (63.6 \pm 20.7 nmole $10^{-9}$ sperm). Then, no significant differences of sperm movement characteristics were measured $2 \mathrm{~h}$ post activation, compared to results observed immediately after activation (data not shown).

In females, a significantly higher number of oocytes $(P=0.001)$ was collected in diploid oysters $\left(19.1 \pm 3.8 \times 10^{6}\right.$ oocytes $)$, than in triploid ones $\left(0.1 \pm 0.1 \times 10^{6}\right.$ oocytes, Fig $\left.2 \mathrm{~A}\right)$. Significantly lower oocyte Feret diameter $(P=0.001)$, perimeter $(P=0.001)$ and area $(P=$ 0.001 ) were recorded for diploid oysters, compared with triploid ones (Fig $2 B, C$ and $D$ ). No significant difference in circularity $(P=0.437)$ was found between oocytes collected from diploid and triploid oysters (data not shown).

D-larval yield was significantly higher $(P=0.001)$ for triploid $\times$ diploid crosses (female $\times$ male), than for the control (diploid $\times$ diploid). Furthermore, the lowest D-larval yield was measured for triploid $\times$ triploid crosses (Fig. 3). 


\section{Discussion}

According to observations carried out in various mollusc species, triploidy leads to partial gonadal development in Pacific oysters, leading to limited reproductive potential, at the different steps of the reproduction process: breeder maturation, gamete biological characteristics and fertilization success.

Examination of breeder maturation observed at the end of the conditioning period revealed that the condition index of triploid oysters was $45 \%$ that of diploid ones. A smaller difference between diploid and triploid oysters had been previously observed (triploid $\mathrm{Cl}=80 \%$ of diploids, estimated on flesh dry weight), but in the context of an exceptionally hot summer that was suggested to enhance gonad development of triploid oysters (Normand et al., 2008). These authors observed that triploid oysters showed normal gametogenesis at early stages but not at later ones, resulting in an incomplete maturation of these oysters. Two types of gametogenic pattern were identified, named $\alpha$, for Pacific oysters unblocked during their gametogenesis and able to produce a significant number of gametes and $\beta$, for individuals presenting locking events during their gametogenesis and producing few or no gametes (Jouaux et al., 2010). At the molecular level, the gametogenesis of $\beta$ individuals slowed down because of impaired sex differentiation caused by the presence of a third set of chromosomes (Dheilly et al., 2014). In northern quahogs, Mercenaria mercenaria, no triploids produced gametes, compared with $82 \%$ of diploid individuals (Eversole et al., 1996). In Pacific oyster, about $25 \%$ of the triploid individuals examined by Jouaux et al. (2010) produced gametes, compared with $42 \%$ in the present work. Environmental conditions such as water temperature or phytoplankton availability may modify the maturation of triploid oysters (Normand et al., 2008; Shpigel et al., 1992).

The description of gamete output in triploid aquatic animals is most often limited to a single parameter, fecundity, which is compared with values from diploid individuals. The number of oocytes observed in gonads of triploid catarian scallop (Argopecten venticosus) was reduced by $82 \%$ compared with that of diploid individuals (Ruiz-Verdugo et al., 2001). After thermal shock, the fecundity of triploid female yesso scallop (Patinopecten yessoensis) was $4 \%$ of the level in diploid females (Meng et al., 2012). In Pacific oyster, the fecundity of triploid females shows a broad variability and appears to depend on the method of production of triploid oysters, namely "chemical" triploids obtained after chemical induction during diploid $x$ diploid mating, or "natural" triploids obtained after diploid $\times$ tetraploid mating. Relative fecundity was estimated to be $2 \%$ of diploid ones, for "chemical" triploids (Guo and Allen, 1994) and $13 \%$ of diploid ones for "natural" triploids (Gong et al., 2004). Knowing that these latter tetraploids were initially produced from selected triploid females with a very high fecundity, according to Gong et al. (2004), mated "natural" triploids may have inherited genes responsible for a high fecundity in triploids through their highly fecund triploid grandmothers. In the present work, although the triploids used were also "natural" ones, a lower relative fecundity corresponding to $0.5 \%$ of diploids was estimated in our triploid females. This could probably be explained by the fact that tetraploids used to produce these triploids were obtained directly from diploid breeders (Benabdelmouna and Ledu, 2007) without any use of highly fecund triploid mothers. Such a strategy probably eliminated or at least lowered significantly the risk of a high fecundity in triploid offspring. To conclude about this question, additional studies using different tetraploid strains, different genetic backgrounds and environmental conditions still need to be conducted.

Sperm production of triploid Pacific oysters was $1.5 \%$ that observed in diploid individuals. Comparative sperm production was not previously estimated in aquatic species, except in Atlantic cod, where no significant differences of sperm density were found between diploid and triploid males (Peruzzi et al., 2009). 
Regarding gamete quality, oocyte diameter was 10\% lower in diploid Pacific oysters compared with triploid ones (Guo and Allen, 1994). This lower size was confirmed in our work by the observation of a lower perimeter $(-11 \%)$ and a lower area $(-20 \%)$, but not by a different in form as observed by the measurement of oocyte circularity. In males, biological characteristics of sperm collected in triploid aquatic species have only been described in Atlantic cod, where no significant differences were recorded between diploid and triploid animals for the percentage of motile spermatozoa and sperm track linearity. Different studies showed sperm movement velocity either not to differ between diploid and triploid cod (Feindel et al., 2010) or to be significantly reduced for triploid animals although only by $9 \%$ (Peruzzi et al., 2009). In the present study, a greater decrease in sperm movement characteristics, assessed 10 minutes post sperm activation, was observed in triploid Pacific oysters compared with diploid individuals: $40 \%$ reduction of motile spermatozoa and $23 \%$ reduction in sperm swimming velocity. Such a decrease in sperm movement characteristics could be explained by the larger size of spermatozoa collected in triploid Pacific oysters, compared to diploid ones (Komaru et al., 1994), leading to different swimming capacities.

In the present work, D-larvae were both obtained by crossing two triploid parents, or one triploid by one diploid. Surprisingly, the D-larval yield obtained for the control (crossing diploid $\times$ diploid breeders; female $\times$ male) was $45 \%$ lower than the results observed when crossing triploid $\times$ diploid breeders although the crosses triploid $\times$ diploid had a lower survival than diploid $\times$ diploid, in the same species (Guo and Allen, 1994). According to this previous paper, using triploid females leads to better survival in the progeny than using triploid males. This could be due to a difference in chromosome inheritance between triploid females and males, the first producing more diploids and triploids and the second more aneuploids (Gong et al., 2004). Then, the D-larval yield of triploid $\times$ triploid crosses was $30 \%$ lower than the result observed for diploid individuals. However, due to limited availability of mature triploid oysters in the present work, the number of crosses was limited, suggesting these trials need to be replicated.

Estimating the reproductive potential of triploid oysters is difficult because of the series of successive steps that have to be considered in the process : Guo and Allen (1994) calculated the reproductive potential of triploid oysters but these authors assume that sperm is not a limiting factor in obtaining progeny from triploids. This is questionable because the present work shows that the total number of sperm collected from triploid oysters was $1.5 \%$ of that recorded in diploids and because a high decrease of sperm movement characteristics, including the percentage of motile sperm and the swimming speed, was also observed. Considering the present data, a partial estimation of the reproductive potential of triploid Pacific oyster (triploid $\times$ triploid crosses) could be close to $0.06 \%$ of the reproductive potential of diploid individuals (taking into account the number of triploid oysters for which gametes could be observed in the gonad compared to diploid individuals: $42 \%$, female fecundity: $0.5 \%$ and D-larval yield: $30 \%$ ). However, this remains an over-estimate result because 1) sperm effect is not taken into account in this result, 2) the oocytes used in the present study were collected after gonad stripping: although spontaneous spawning of triploid Pacific oysters has been previously recorded (Allen and Downing, 1990; Shpigel et al., 1992), this phenomenon is poorly documented in natural conditions and its frequency is unknown, and, 3) the progeny resulting from crosses of triploids is mostly composed of aneuploids with a low viability (Guo and Allen, 1994): this has been confirmed by the long-term survival rate estimated from fertilized oocytes to spat stage, ranging from $0.007 \%$ (diploid $\times$ triploid crosses) to $0.314 \%$ (triploid $\times$ diploid), depending on crosses (Gong et al., 2004).

Compared to diploid ones, the low reproductive potential generally observed in triploid oysters and confirmed in the present study, has several consequences. A higher growth rate is reported in triploid oysters because energy is not diverted towards reproduction. The farming of triploid oysters in an open sea environment largely decreases the possible genetic impact on natural populations but also the rapid expansion of Pacific oyster, often considered 
as an invasive species (Troost, 2010). Triploidy could be considered as a safeguard against competition imposed on native populations. However, no evidence was reported that Pacific oyster invasive behaviour impaired biodiversity or ecosystem functioning (Reise et al., 2006). Then, the production of "natural" triploid oysters, obtained after diploid $\times$ tetraploid mating, requires the maintenance of tetraploid broodstocks. Such oyster stocks may modify hatchery practices: tetraploid oysters must be held in quarantine because there is a risk of potential impacts following the escape of gametes and larvae (Piferrer et al., 2009). Artificial insemination routine must also be modified, taking into account the lower sperm quality observed in tetraploid Pacific oysters, compared to diploid ones (Suquet et al., 2009).

In conclusion, the present work confirms the low reproductive potential of triploid Pacific oysters estimated in previous studies. Because molluscs are generally farmed in open systems, triploidy reduces but does not totally suppress, the possible "genetic pollution" of wild populations. The effect of changes in environmental conditions, especially global warming, on the reproductive potential of triploid Pacific oyster must now be studied.

\section{Acknowledgments}

The authors acknowledge the financial support of Direction des Pêches Maritimes et Aquaculture (DPMA), project Caryocyto. We also thank the hatchery and nursery teams of Ifremer La Tremblade, Ifremer Bouin and Ifremer Argenton for their assistance with oyster production.

\section{References}

Allen Jr., S.K., Downing, S.L., 1990. Performance of triploid Pacific oysters, Crassostrea gigas: gametogenesis. Can. J. Fish. Aquat. Sci. 47, 1213-1222.

Barranger, A., Akcha, F., Rouxel, J., Brizard, R., Maurouard, E., Pallud, M., Menard, D ., Tapie, N., Budzinski, H., Benabdelmouna, A., 2014. Study of genetic damage in the Japanese oyster induced by an environmentally-relevant exposure to diuron: Evidence of vertical transmission of DNA damage. Aquat. Toxicol. 146, 93-104.

Benabdelmouna, A., Ledu, C., 2007. Obtention de mollusques bivalves tétraploïdes à partir de géniteurs diploïdes. Patent FR2913982A1.

Dheilly, N.M., Jouaux, A., Boudry, P., Favrel, P., Lelong, C., 2014. Transriptomic profiling of gametogenesis in triploid Pacific oysters Crassostrea gigas: towards an understanding of partial sterility associated with triploidy. Plos one 9 (11).

Dunham, R.A., 2011. Aquaculture and fisheries biotechnology, $2^{\text {nd }}$ ed. Cabi, Wallingford, UK.

Eversole, A.G., Kempton, C.J., Hadley, N.H., Buzzi, W.R., 1996. Comparison of growth, survival, and reproductive success of diploid and triploid Mercenaria mercenaria. J. Shellfish Res. 15, 689-694.

Fauvel, C., Suquet, M., Cosson, J., 2008. Evaluation of fish sperm quality. J. Appl. Ichthyol. 26, 636-643.

Feindel, N.J., Benfey, T.J., Trippel, E.A., 2010. Competitive spawning success and fertility of triploid male Atlantic cod Gadus morhua. Aquac. Env. Inter. 1: 47-55.

Gong, N., Yang, H., Zhang, G., Landau, B.J., Guo, X., 2004. Chromosome inheritance in triploid Pacific oyster Crassostrea gigas Thunberg. Heredity 93, 408-415.

Guo, X., Allen Jr., K., 1994. Reproductive potential and genetics of triploid Pacific oysters, Crassostrea gigas (Thunberg). Biol. Bull. 187, 309-318. 
Guo, X., De Brosse, G.A., Allen Jr., K.A., 1996. All triploid Pacific oysters (Crassostrea gigas) produced by mating tetraploids and diploids. Aquaculture 142, 149-161.

Jouaux, A., Heude-Berthelin, C., Sourdaine, P., Mathieu, M., Kellner, K., 2010. Gametogenic stages in triploid oysters Crassostrea gigas: irregular locking of gonial proliferation and subsequent reproductive effort. J. Exp. Marine Biol. Ecol. 395, 162-170.

Komaru, A., Konishi, K., Wada, K.T., 1994. Ultrastructure of spermatozoa from induced triploid Pacific oyster, Crassostrea gigas. Aquaculture 123, 217-222.

Meng, Q., Bao, Z., Wang, Z., Wang, S., Hu, J., Hu, X., Huang, X., 2012. Growth and reproductive performance of triploid yesso scallops (Pactinopecten yessoensis) induced by hypotonic shock. J. Shellfish Res. 31, 1113-1122.

Nell, J.A., 2002. Farming triploid oysters. Aquaculture 210, 69-88.

Normand, J., Le Pennec, M., Boudry, P., 2008. Comparative histological study of gametogenesis in diploid and triploid Pacific oysters (Crassostrea gigas) reared in an estuarine farming site in France during the 2003 heatwave. Aquaculture 282, 124129.

Perruzzi, S., Rudolfsen, G., Primicerio, R., Frantzen, M., Kauric, G., 2009. Milt characteristics of diploid and triploid Atlantic cod (Gadus morhua L.) Aquac. Res. 40, 1160-1169.

Piferrer, F., Beaumont, A., Falguière, J.C., Flajshans, M., Haffray, P., Colombo, L., 2009. Polyploid fish and shellfish: Production, biology and applications to aquaculture for performance improvement and genetic containment. Aquaculture 293, 125-156.

Reise, K., Olenin, S., Thieltges, D.W., 2006. Are aliens threatening European aquatic coastal ecosystems? Helgol. Mar. Res. 60, 77-83.

Royer, J., Seguineau, C., Park, K-II, Pouvreau, S., Choi, K.S., Costil, K., 2008. Gametogenic cycle and reproductive effort assessed by two methods in 3 age classes of Pacific oysters, Crassostrea gigas, reared in Normandy. Aquaculture 277, 313-320.

Ruiz-Verdugo, C.A., Allen Jr., S.K., Ibarra, A.M., 2001. Family differences in success of triploid induction and effects of triploidy on fecundity of catarina scallop (Argopecten ventricosus). Aquaculture 201, 19-33.

Sellars, M., Wood, A., Murphy, B., Coman, G., Arnold, S., McCulloch, R., Preston, N., 2013. Reproductive performance and mature gonad morphology of triploid and diploid black Tiger shrimp (Penaeus monodon) siblings. Aquat. Res. 44, 1493-1501.

Shpigel, M., Barber, B.J., Mann, R., 1992. Effects of elevated temperature on growth, gametogenesis, physiology, and biochemical composition in diploid and triploid Pacific oysters, Crassostrea gigas Thunberg. J. Exp. Mar. Biol. Ecol. 161, 15-25.

Song, Y.P., Suquet, M., Quéau, I., Lebun, L., 2009. Setting of a procedure for experimental fertilisation of Pacific oyster (Crassostrea gigas) oocytes. Aquaculture 287, 311-314.

Stanley, J.G., Allen, Jr., S.K., Hidu, H., 1981. Polyploidy induced in the American oyster, Crassotrea virginica, with cytochalasin B. Aquaculture 23, 1-10.

Suquet, M., Donval, A., Labbé, C., Brizard, R., Le Coz, J.R., Quere, C., Robert, R., Benabdelmouna, A., Haffray, P., 2009. Sperm qualty in diploid and tetraploid Pacific oysters, Crassostrea gigas. In: Aquaculture Europe 09, New research frontiers, EAS Sp. Publ., pp. 525-526.

Suquet, M., Labbé, C., Puyo, S., Mingant, C., Quittet, B., Boulais, M., Queau, I., Ratiskol, D., Diss, B., Haffray, P., 2014. Survival, growth and reproduction of cryopreserved larvae from a marine invertebrate, the Pacific oyster (Crassostrea gigas). Plos one 9 (4).

Troost, K., 2010. Causes and effects of a highly successful marine invasion: Case-study of the introduced Pacific oyster Crassostrea gigas in continental NW European estuaries. J. Sea Res. 64, 145-165. 


\section{Figures}

Fig. 1. Sperm characteristics of diploid and triploid oysters. A) Total number of spermatozoa collected, B) Percentage of motile sperm, C) Sperm velocity, VAP: Velocity of the Average Path (different letters indicate significantly different results).
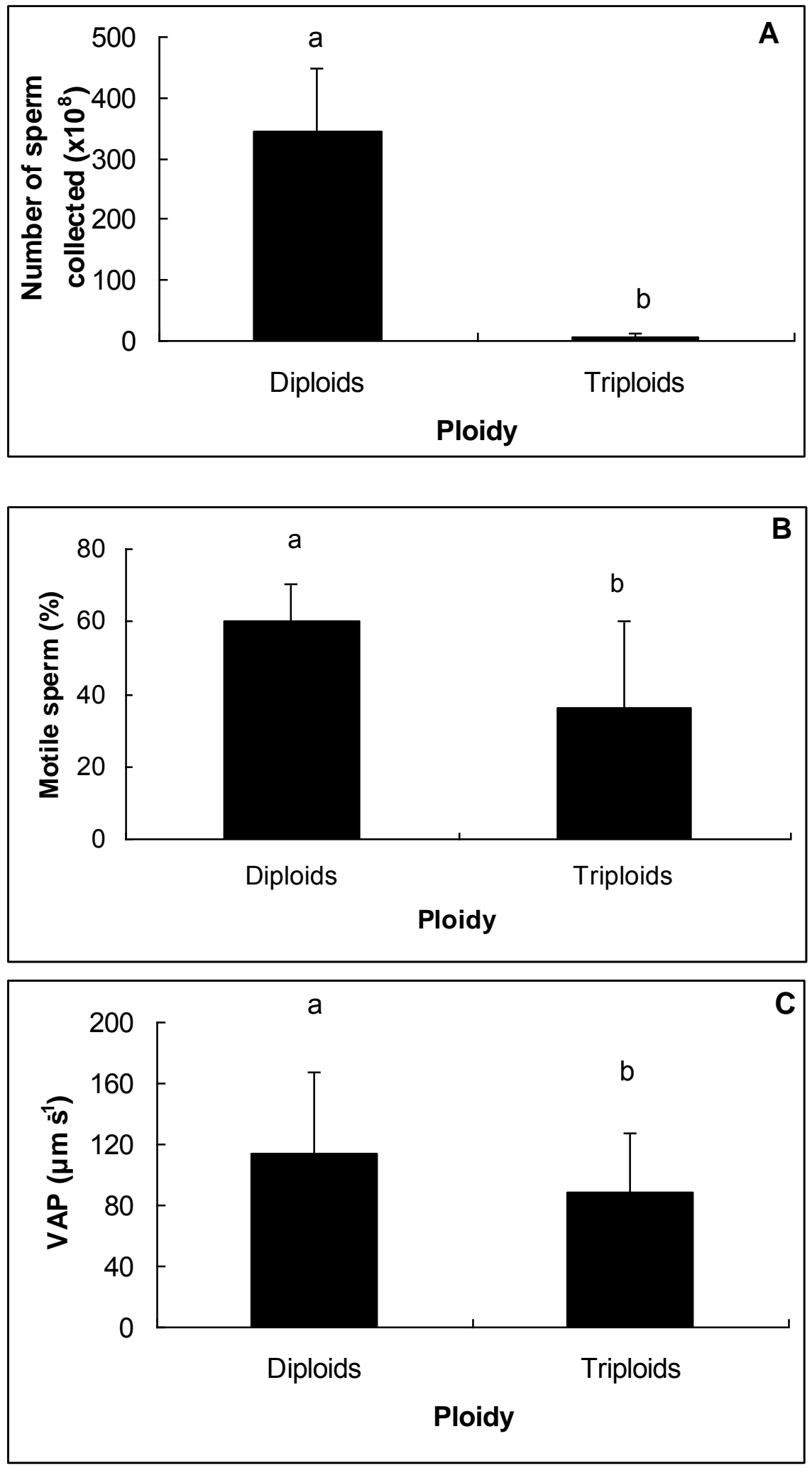
Fig. 2. Oocyte characteristics of diploid and triploid oysters. A) Total number of oocytes collected, B) Feret diameter, C) Perimeter, D) Area (different letters indicate significantly different results).
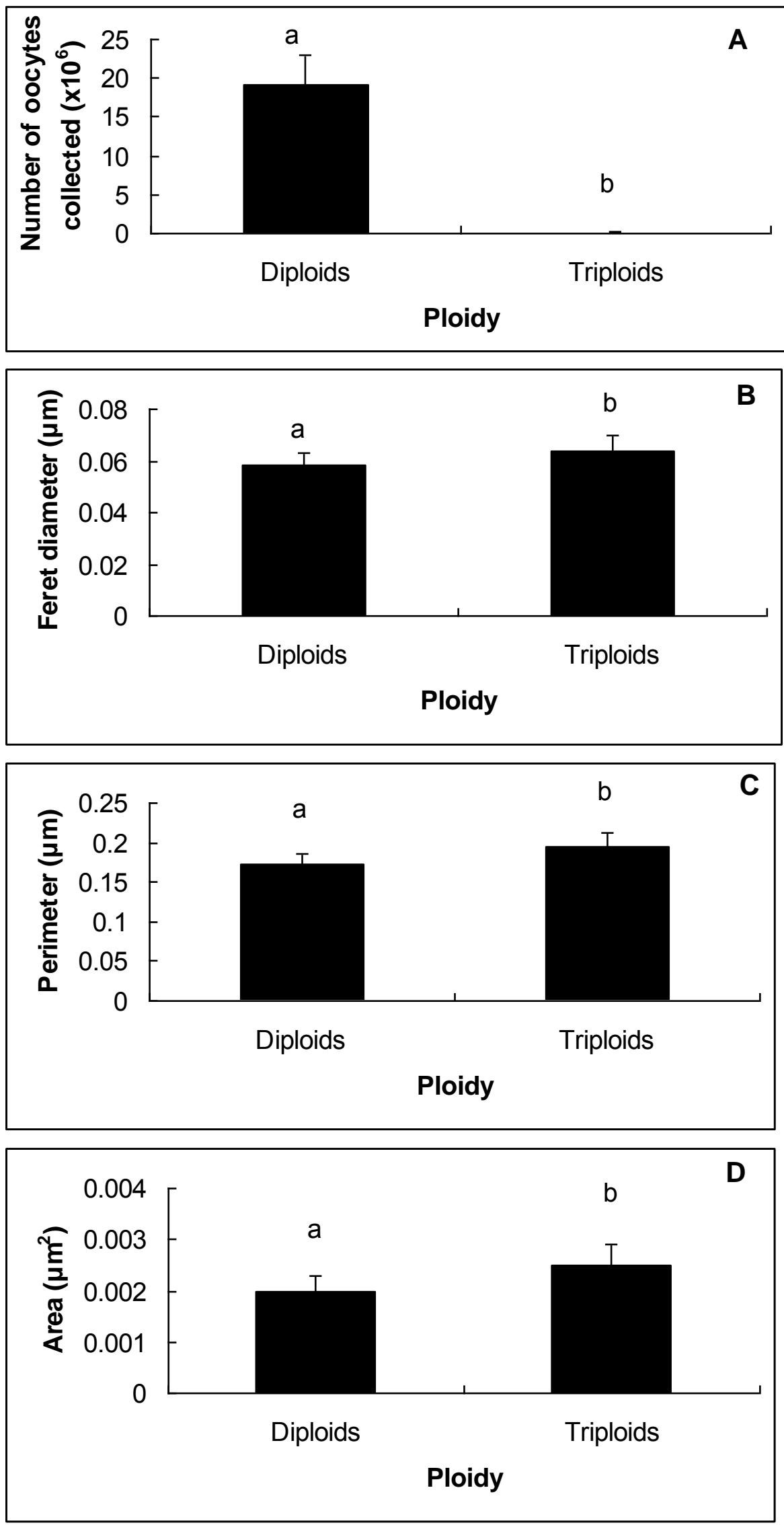
Fig. 3. Effect of oyster ploidy (diploid: 2, triploid: 3) on subsequent D-larval rate (different letters indicate significantly different results).

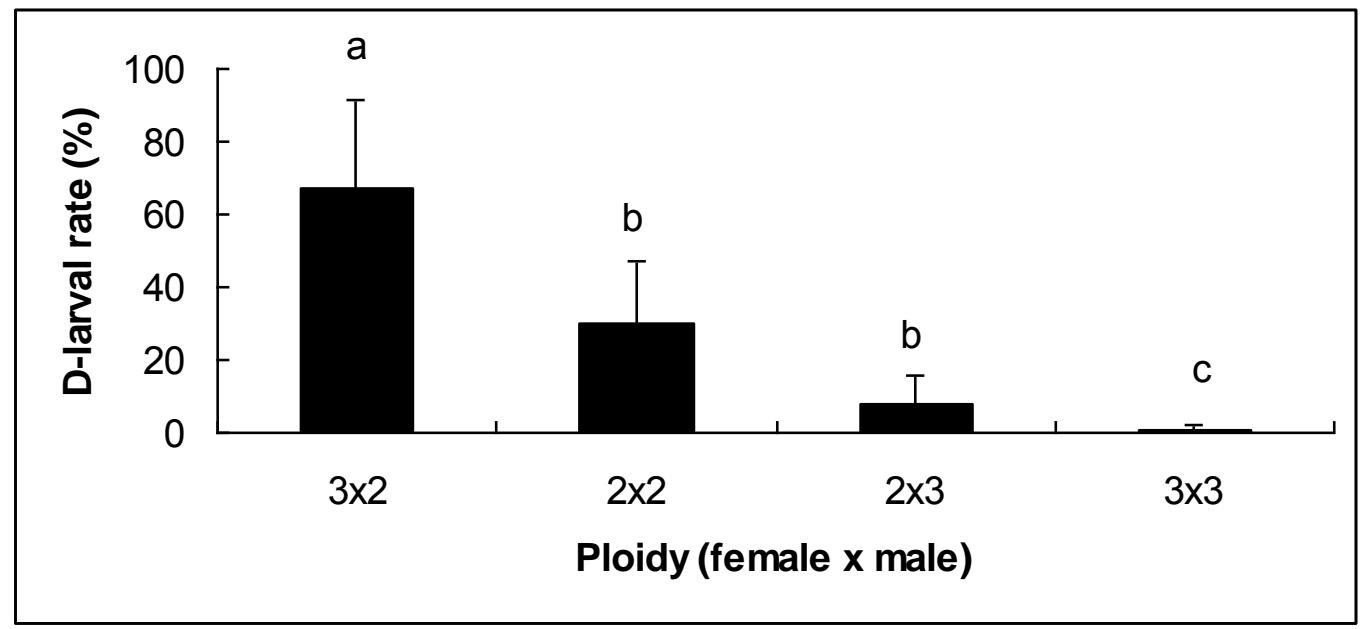

